\title{
Reflexões sobre as indisciplinaridades
}

\section{Considerations on indisciplinarities}

\author{
Eduardo Nazareth Paiva \\ Programa de Pós-Graduação em História das Ciências e das Técnicas e Epistemologia \\ (HCTE), Universidade Federal do Rio de Janeiro (UFRJ) \\ edu@hcte.ufrj.br \\ orcid.org/0000-0003-0191-4501
}

\section{Cláudia Santos Turco}

Programa de Pós-Graduação em História das Ciências e das Técnicas e Epistemologia (HCTE), Universidade Federal do Rio de Janeiro (UFRJ)

claudia.turco@hcte.ufrj.br

orcid.org/0000-0002-4792-8282

\begin{abstract}
Resumo. Comungando e algumas vezes parafraseando pensadores como Eduardo Viveiros de Castro, ensaiamos pensar a tecnociência como uma coisa indisciplinada buscando usá-la como estratégia para a autodeterminação de coletivos locais. Isso possui algumas diferenças daquelas estratégias que praticamente buscam ou encontram a autoextinção em troca de legados outros. Não é fácil nem normal se buscar dimensões coletivas-relacionais da realidade local sem tentar universalizá-las. O trabalho tece considerações sobre como elaborar pensamentos simétricos sobre conceitos em construção ou estabelecidos e pensa a indisciplinaridade como uma estratégia desenvolvida à luz da pertinência, da comunhão e das potencialidades dos interesses locais, resistindo às pressões para subalterná-los diante dos conhecimentos universalizantes.
\end{abstract}

Palavras-chave: Indisciplinaridades. Traduções/Translações. CTS.

Abstract. Communing and sometimes paraphrasing thinkers as Eduardo Viveiros de Castro, we tried to thinking about technoscience as an undisciplined thing seeking to use it as a strategy for local collectives self-determination. This has some differences from those strategies that practically seek or find self-extinction in other legacies. It is neither easy nor normal to look for collective-relational dimensions of local reality without trying to universalize them. The work makes considerations about how to elaborate symmetrical thoughts about concepts under construction or established and thinks about indisciplinarity as a strategy developed in the light of pertinence, 
communion and the potential of local interests, resisting the pressures to subordinate them in the face of universal knowledge.

Keywords: Indisciplinarities. Translations. CTS.

Recebido: 01/10/2017 Aceito: 27/10/10 Publicado: 05/11/2017

\section{Informações gerais}

Em palestra proferida na Universidade Federal de Minas Gerais / UFMG, Eduardo Viveiros de Castro (2005) coloca a antropologia como uma disciplina que até bem pouco tempo atrás estava voltada para o estudo de sociedades não especializadas, não separadas por esferas do saber, em suma, indisciplinares e indisciplinadas. A antropologia se definiria como a ciência da não-ciência, o que imprime à antropologia da ciência um caráter reflexivo. A antropologia da ciência traz, também um certo incômodo ao colocar os objetos da tecnociência e as ditas superstições e mitos sob um mesmo olhar, de forma simétrica.

Ao observar as práticas científicas nestas condições, percebe-se que a estabilização de fatos não é uma atividade neutra, simples ou fácil; esta envolve cooperação, não apenas entre pares mas também com outros atores; estes habitantes de múltiplos mundos sociais. É também comum que os próprios objetos de estudo habitem e circulem em diferentes mundos sociais, que sejam transdisciplinares ou ainda, nas palavras de Eduardo Viveiros de Castro, que "desrespeitem indisciplinadamente a multissecular e sacrossanta fronteira entre as ciências da extensão e as ciências do pensamento ou, para falarmos modernamente, entre as ciências da natureza e as ciências da cultura ou da alma - as humanidades" (CASTRO, 2010).

No entanto, essa cooperação ou ação simultânea demanda um árduo e permanente trabalho, que envolve todos os atores implicados para que se estabeleça e se estabilize um fato científico. Este esforço de tradução e deslocamento merece algumas reflexões e este trabalho buscará percorrer alguns conceitos que ajudam a entender estas transições e passeios entre-mundos; conceitos que podem ser úteis para entender ou explicitar assimetrias seja entre os mundos científicos-disciplinares, seja entre estes e outros mundos, ditos leigos.

\section{Traduções, modalidades e interessamento}

Latour (2011) apresenta a construção de fatos na tecnociência como um processo de retórica, no qual traduções e deslocamentos de significado ocorrem entre cientistas e não cientistas, o que pode levar à desistência, à aceitação ou à manutenção dos debates em torno de determinadas proposições ao longo do tempo. Neste processo, laboratórios são construídos, artigos são escritos e aliados são arregimentados. 
O problema da tradução foi colocado por Latour $(2011,2016)$ e Callon (1984) e, em suas origens, tem seu olhar dirigido para a tradução das preocupações dos cientistas para aquelas dos não-cientistas, ou seja, é o processo pelo qual cientistas buscam criar autoridade científica, através da busca de aliados de várias origens (LATOUR, 2011) e se estabelecer como pontos de passagem obrigatórios. Este é o chamado interessamento, no sentido de inter-esse, o que se situa entre duas coisas, entre os atores e seus objetivos. Neste caso, traduz interesses de diversos atores, de mundos sociais múltiplos. Segundo Latour (2016), a ciência será ou não interessante dependendo de sua habilidade de composição com outros cursos de ação, aceitando os desvios necessários, assim como de sua capacidade de se fazer reconhecer como fonte principal da proposição resultante de todo o processo de tradução. Para Latour, "tradução é ao mesmo tempo transcrever, transpor, deslocar, transferir e, portanto, transportar transformando" ( 2016, p.30).

Callon (1984) nos apresenta a sociologia da tradução como um estudo de poder e o próprio processo de tradução como nunca completamente atingido e passível de fracasso. Sua análise sobre controvérsias parte de três princípios: a imparcialidade entre os atores implicados em uma controvérsia; a simetria ao analisar diferentes pontos de vista; e o abandono da dicotomia natural/social.

A percepção da tradução ocorre quando se acompanha cientistas, seu diálogo com outros atores e as modalidades de discurso que surgem ao se elaborar, ao longo deste processo, as proposições. Todos os atores implicados no processo de tradução atuam sobre a proposição, não apenas transmitindo, mas acrescentando elementos e modificando o argumento de forma a incorporá-Io em novos contextos. Neste sentido, fatos e proposições são coletivamente construídos e compostos pelos atores. Nesta ação coletiva cada ator seleciona, entre as possibilidades e modalidades existentes, as características que os ajudem a alcançar seus objetivos, o que, ao final do processo, cria um desvio entre a proposição inicial e a final. Aí podem ocorrer traições.

Se analisarmos os discursos dos atores implicados em determinado processo de tradução, veremos que acontecem modalidades positivas e negativas. Modalidades positivas são aquelas que empurram o enunciado inicial para a estabilidade, afastando-o de suas condições de produção. As modalidades negativas já aproximam o enunciado inicial de suas condições de produção, explicitando as razões e suas forças e fraquezas. Assim, através desta construção conjunta, por vezes envolvendo intensas disputas, uma sentença flui mais da condição de fato para a ficção ou vice-versa.

O modelo traz como principais questões para análise o fluxo de objetos e conceitos através de uma rede de aliados e de mundos sociais, sua busca por enquadrar e afunilar as preocupações e os interesses de diversos atores para um único ponto de passagem. Assim, apenas seguindo as sinuosidades da ação coletiva, através dos desvios e composições, pode-se encontrar os diversos atores e elementos e compreender seu papel no processo de tradução. 


\section{Mundos sociais, objetos de fronteira e agentes intermediários}

Clarke e Star (2008) definem mundo social como universos de discurso, espaços compartilhados de discurso que são profundamente relacionais. Inicialmente utilizado na década de 1970 em estudos de sociologia urbana nos quais a dimensão territorial era crucial, o uso do conceito foi ampliado para o entendimento de outros grupos, nacionais e internacionais, como profissões ou mesmo uma tradição teórica, por exemplo. Neste sentido, mundos sociais formam a base para uma ação coletiva, seus participantes estão comprometidos com certas atividades, compartilham objetivos e constroem suas próprias identidades.

Quando diferentes mundos sociais chegam a uma interseção e se encontram em torno de questões de interesse e compromisso mútuo, pode-se analisar como se estivessem em uma arena. E claro, muito esforço é também despendido em demarcar as fronteiras entre estes diferentes mundos.

O conceito de mundo social pode ser utilizado para entender a emergência de novas disciplinas ou especialidades. Diferentes disciplinas são entendidas como diferentes mundos sociais, que, em determinados momentos, podem se recombinar através de consenso ou cooperação para criar uma nova disciplina, como por exemplo, os estudos ambientais. No entanto, a interação entre atores de diferentes mundos sociais pode ocorrer independente de consenso, ou seja, atores de diferentes mundos sociais podem colocar suas diferenças de lado - mesmo que temporariamente - em prol de uma ação coletiva, dialogicamente.

O conceito de mundo social foi amplamente utilizado nos estudos CTS. Ao longo do tempo, estas análises incorporaram os conceitos de ação situada (HARAWAY, 1995) e de análise do discurso (FOULCAULT, 2009), criando o que pode ser denominado de análise situada. A análise situada é entendida como a percepção de que as condições em que a ação acontece são a própria ação, eliminando a separação ação/contexto. A situação é a própria unidade de análise, na qual são situados mundos sociais, arenas, atores e relações. Colocar a ação no centro da análise facilita a compreensão dos diversos mundos sociais, pois a partir da ação central é possível seguir os diferentes atores e interesses que dela partem.

Para a análise de diferentes mundos sociais e de suas interseções, Star e Griesemer (1989) propõem o conceito de objetos de fronteira. Esses objetos, físicos ou conceituais, seriam flexíveis o suficiente para habitar múltiplos mundos sociais, mas, ao mesmo tempo, robustos o suficiente para manter algum nível de identidade em todos eles. Os objetos de fronteira são entendidos não apenas como meio de tradução, mas também como a formação e expressão de uma identidade (CLARKE; STAR, 2008). Neste sentido, são conceitos ou objetos que auxiliam tanto a tradução e a transição entre mundos, quanto a demarcação de suas fronteiras.

Outro conceito proposto para a análise de traduções e deslocamentos entre mundos sociais é o de agentes intermediários. As pessoas participam, simultaneamente, em diferentes mundos sociais e os agentes intermediários conseguem, ao participar destes 
mundos, realizar conexões e coordenar possibilidades de troca. Neste sentido, sua atuação ocorre em processos de tradução e coordenação que, ao longo do tempo, podem se desenvolver em um conjunto de recursos compartilhados entre mundos sociais distintos, que se cristalizam em regras, procedimentos e, mesmo, em objetos de fronteira a serem utilizados.

O modelo de Star e Griesemer (1989) adota e amplia o modelo de interessamento de Latour (2011, 2016) e Callon (1984), assumindo que há vários atores, provenientes de mundos sociais diversos, que buscam fazer suas traduções simultaneamente. Portanto, o processo de tradução não pode ser entendido por um único ponto de vista - o do cientista - e sim deve ser analisado do ponto de vista ecológico, de forma nãoreducionista. Assim, o modelo de Star e Griesemer (1989) implica na possibilidade de coexistência de vários pontos de passagem obrigatórios e de múltiplos conjuntos coerentes de tradução simultâneos.

\section{Uma ciência indisciplinada, de indisciplinados para indisciplinados}

Em palestra proferida em 2010, na UFMG, Eduardo Viveiros de Castro se coloca como um pesquisador que não tem uma prática transdisciplinar, que não realiza estudos antropológicos da ciência, mas de sociedades que são rotuladas, injustamente, como simples. $\mathrm{O}$ autor nos traz, então, a proposta de uma antropologia indisciplinada ou uma antropologia da indisciplinaridade. Uma disciplina que até bem pouco tempo atrás estava voltada para o estudo de sociedades não especializadas, não separadas por esferas do saber, em suma, indisciplinares e indisciplinadas. Portanto a antropologia se define como a ciência da não-ciência, o que dá à antropologia da ciência um caráter reflexivo e cuja ação traz um certo incômodo.

Viveiros de Castro (2010) coloca que a obra de Lévi-Strauss e seu estudo sobre o estilo intelectual das sociedades ameríndias permitiu entender o pensamento selvagem como um pensamento insubmisso, indisciplinado. É essa compreensão que abre a possibilidade de criar estas multiplicidades e mesmo uma forma de descriar imperialidades. Talvez um importante papel da antropologia seja criar condições para a auto-determinação conceitual dos povos.

O que o autor propõe é uma supersimetria entre cientistas e outros saberes. É o abandono da noção de que, no caso da antropologia, a ciência do antropólogo é de outra ordem que a ciência do nativo. Afirmar esta diferença, para o autor seria cometer um "epistemocídio" e escapar desta divisão é entrar no "mundo do meio", no mundo relacional. O antropólogo deveria assumir que o discurso destes outros saberes fala sobre o mundo, assim como o discurso das próprias ciências. São discursos provenientes de diferentes ontologias, os verdadeiros objetos da antropologia.

As formas de compreender as interseções entre diferentes mundos sociais, os caminhos do meio e seus processos de tradução, seja entre diferentes disciplinas ou seja entre ciências e saberes leigos, de forma simétrica ou supersimétrica, afastam nossos estudos 
de dicotomias radicais e de fronteiras demarcadas. Esta perspectiva afasta, ainda, os estudos das acusações de irracionalidade, abrindo espaço para a multiplicidade de discursos e saberes. Talvez essas escolhas nos aproximem mais das culturas ditas simples, indisciplinadas e insubordinadas.

Finalmente, no âmbito do próprio conhecimento dito científico, estes conceitos, esta indisciplinaridade e insubordinação podem nos ajudar a superar o que Polanco (1986) denominou de fuga interna de cérebros. Por esta expressão, o autor busca explicitar a posição assumida por pesquisadores da América Latina e de outros países que, mesmo sem sair de seus países, orientam seus trabalhos de investigação e seus sistemas de avaliação em função dos problemas e programas de pesquisa definidos externamente. Melhor seria trazer a reflexão nas palavras de Darcy Ribeiro, lembradas por Sugimoto (2017).

\begin{abstract}
"A crítica de Darcy Ribeiro era de que a antropologia tinha rompido seu compromisso com os povos que estudava, em especial com os indígenas. Endurecia o verbo, acusando os antropólogos, por exemplo, de terem se tornado "cavalos de santo" - aqueles que nos cultos afros são tomados por entidades que vêm falar por meio deles. "No caso, os antropólogos eram tomados por entidades do 'primeiro mundo', limitando-se a repetir em suas teses o que falavam os grandes intelectuais lá de fora"
\end{abstract}

É esta reflexão que queremos compartilhar com você, que nos leu até aqui.

\title{
Financiamento
}

O presente trabalho foi realizado com apoio da Coordenação de Aperfeiçoamento de Pessoal de Nível Superior - Brasil (CAPES) - Código de Financiamento 001.

\section{Referências}

CALLON, Michel. Some Elements of a Sociology of Translation: Domestication of the Scallops and the Fishermen of St Brieuc Bay. The Sociological Review, 32, no 1_suppl, maio de 1984, p. 196-233. doi:10.1111/j.1467-954X.1984.tb00113.x.

CASTRO, Eduardo Viveiros de. Antropologia e imaginação da indisciplinaridade. Instituto de Estudos Avançados Transdisciplinares (UFMG), Youtube, 24 de ago. 2010. Disponível em https://www.youtube.com/watch?v=ry1ykrRVqYk\&t=29s . Acesso em 4 out. 2017.

CLARKE, Adele; STAR, Susan Leigh . The Social Worlds Framework: A Theory/Methods Package, 2008. doi:10.1002/9780470377994.ch6. 
FOUCAULT, Michel A Ordem do Discurso. Aula Inaugural no Collège de France, pronunciada em 2 de dezembro de 1970. 19.ed. São Paulo: Edições Loyola, 2009.

FUJIMURA, Joan H. Crafting Science: Standardized Packages, Boundary Objects, and 'Translation'. In: PICKERING, Andrew (Org.). Science as Practice and Culture. Chicago: University of Chicago Press, 1992. P. 168-211.

HARAWAY, Donna. Saberes localizados: a questão da ciência para o feminismo e o privilégio da perspectiva parcial.Cadernos Pagu, Campinas, SP, n. 5, p. 7-41, jan. 2009. ISSN 1809-4449. Disponível em: <https://periodicos.sbu.unicamp.br/ojs/index.php/cadpagu/article/view/1773>. Acesso em: 08 out. 2017.

HUVILA, Isto. The Politics of Boundary Objects: Hegemonic Interventions and the Making of a Document. Journal of the Association for Information Science and Technology, v. 62, n. 12 , p. 2528-2539, 1o de dezembro de 2011. doi:10.1002/asi.21639.

KIMBLE, Chris; GRENIER, Corinne; GOGLIO-PRIMARD, Karine. Innovation and knowledge sharing across professional boundaries: Political interplay between boundary objects and brokers. International Journal of Information Management, v. 30, n. 5, 2010. Disponível em: https://works.bepress.com/chris_kimble/10/. Acesso em: 4 out. 2017.

LATOUR, B. A ciência em ação: como seguir cientistas e engenheiros mundo afora. São Paulo: Ed. UNESP, 2011.

LATOUR, Bruno. Cogitamus: seis cartas sobre as humanidades científicas. Trad. Jamille Pinheiro Dias. São Paulo: Ed.34, 2016.

POLANCO, Xavier. La ciencia como ficción. Historia y contexto, In: Cuadernos de Quipu, El Perfil de la Ciencia en América, Saldaña, J.J. (org), n. 1. Mexico, Sociedad Latinoamericana de Historia de las Ciencias y la Tecnología, 1986.

STAR, Susan Leigh. This Is Not a Boundary Object: Reflections on the Origin of a Concept. Science, Technology, \& Human Values, v, 35, n.. 5, p. 601-617, setembro de 2010. doi:10.1177/0162243910377624. 
STAR, S.L, GRIESEMER, J.R., Institutional Ecology, 'Translations' and Boundary Objects: Amateurs and Professionals in Berkeley's Museum of Vertebrate Zoology, 1907-39. Social Studies of Science, v. 19, n. 3, p.387-420, Agosto de 1989. Disponível em https://www.jstor.org/stable/285080?seq=1\#page_scan_tab_contents. Acesso em 4 de out de 2017.

SUGIMOTO, L. Um brasileiro no exílio. E um exilado no Brasil. Jornal da Unicamp, Campinas, p.12, 9ª 15 abr.2007 